\title{
Atividade antagônica a microrganismos patogênicos por bactérias endofíticas isoladas de Echinodorus scaber Rataj
}

\author{
Ricardo Douglas de Souza ${ }^{1}$, Elisabeth Aparecida Furtado de Mendonça ${ }^{1}$, Marcos Antônio Soares ${ }^{2}$
}

${ }^{1}$ Programa de Pós-Graduação em Agricultura Tropical - Universidade Federal de Mato Grosso , 78060-900, Cuiabá, MT, Brasil. ${ }^{2}$ Laboratório de Biotecnologia e Ecologia Microbiana - LABEM, Universidade Federal de Mato Grosso, 78060-900, Cuiabá, MT, Brasil. Parte da dissertação do primeiro autor.

Autor para correspondência: Marcos Antônio Soares (drmasoares@gmail.com)

Data de chegada: 22/05/2014. Aceito para publicação em: 04/05/2015.

$10.1590 / 0100-5405 / 2010$

\section{RESUMO}

Souza, R.D.; Mendonça, E.A.F., Soares, M.A.. Atividade antagônica a microrganismos patogênicos por bactérias endofíticas isoladas de Echinodorus scaber Rataj. Summa Phytopathologica, v.41, n.3, p.229-232, 2015.

Os objetivos desse trabalho foram identificar e avaliar o potencial antagônico in vitro de bactérias endofíticas isoladas de Echinodorus scaber (chapéu de couro) sobre alguns patógenos e verificar sua capacidade de controlar o desenvolvimento de fungos em grãos de soja. Um total de 113 linhagens foi confrontado com cinco fungos patogênicos (método de cultura dupla), e quatro bactérias patogênicas (método de sobrecamada). O controle de crescimento de fungo em grãos de soja foi realizado por microbiolização e avaliado pelo método de papel de filtro. As bactérias antagonistas foram submetidas a teste de antibiose contra quatro bactérias patógenas. Duas linhagens inibiram os fungos Colletotrichum lindemunthianum, C. gloeosporioides, Corynespora cassiicula, Fusarium solani, Microsporum canis. No teste de antibiose contra as bactérias patogênicas somente (BREIII-107) apresentou atividade antagônica. As duas linhagens e foram identificadas como Bacillus sp (BREI-92) e Bacillus subitilis (BREIII-107). Quando inoculadas em grãos de soja, Bacillus sp (BREI92) e Bacillus subitilis (BREIII-107) inibiram aproximadamente $100 \%$ do desenvolvimento de fungos sobre os grãos.

Palavras-chave: Bacillus sp. Controle Biológico. Glycine max.

\section{ABSTRACT}

Souza, R.D.; Mendonça, E.A.F., Soares, M.A.. Antagonistic activity to pathogenic microorganisms by endophytic bacteria isolated from Echinodorus scaber Rataj. Summa Phytopathologica, v.41, n.3, p.229-232, 2015.

The aims of this study were to identify and evaluate the in vitro antagonistic potential of endophytic bacteria isolated from Echinodorus scaber ("chapéu de couro") on some pathogens and to verify their capability of controlling the growth of fungi in soybean seeds. A total of 113 strains were confronted with five pathogenic fungi (dual culture method) and four pathogenic bacteria (overlay method). The fungal growth control in soybeans was carried out by microbiolization and evaluated by the filter paper method. The antagonistic bacteria were subjected to antibiosis test against four pathogenic bacteria. Two strains inhibited the fungi Colletotrichum lindemunthianum, C. gloeosporioides, Corynespora cassiicula, Fusarium solani, Microsporum canis. In the antibiosis test against pathogenic bacteria, only BREIII-107 showed antagonistic activity. The two strains were identified as Bacillus sp (BREI-92) and Bacillus subitilis (BREIII-107). When inoculated in soybeans, Bacillus sp (BREI92) and Bacillus subitilis (BREIII-107) inhibited approximately $100 \%$ of fungal growth on the seeds.

Additional keywords: Bacillus sp., Biological Control, Glycine max.

Microrganismos endofíticos, segundo Bacon e Hinton (2), colonizam o tecido vegetal, formando associações mutualísticas de longo prazo, sem apresentar nenhum dano evidente ao hospedeiro.

Diversos trabalhos demonstram a potencialidade deste grupo de microrganismo em sintetizarem metabólitos especiais constituindo novas fontes de compostos bioativos, aplicáveis em diferentes áreas, como na indústria agrícola ou farmacêutica (1).

Grande parte do sistema de produção vigente no Brasil utiliza produtos químicos no controle de doenças causadas por fitopatógenos com o objetivo de reduzir as perdas resultantes de doenças. Apesar dos fungicidas químicos reduzirem o nível de infecção de fungos em sementes, o tratamento recorrente com esses produtos pode selecionar linhagens resistentes a alguns grupos fungicidas.

Echinodorus scaber Rataj é uma planta conhecida popularmente no Brasil por seu uso medicinal e ornamental, denominada pelas populações como chapéu de couro. Essa espécie é usualmente utilizada para o tratamento de várias enfermidades como: reumatismo, tratamento de ácido úrico, sífilis, doenças de pele e de fígado e também para fins diuréticos (11).

Esta pesquisa teve como objetivo selecionar in vitro bactérias endofíticas antagônicas a patógenos, isoladas de Echinodorus scaber (chapéu de couro) e determinar a capacidade de controle biológico no desenvolvimento de patógenos pós-colheita em grãos de soja.

Um total de 113 isolados de bactérias endofíticas, obtidas do tecido interno das raízes de E. scaber Rataj foi utilizado para seleção de linhagens de interesse com potencial antagônico.

$\mathrm{O}$ antagonismo de bactérias endofíticas foi avaliado contra cinco espécies de fungos: Colletotrichum lindemunthianum, agente causal 
da antracnose do feijoeiro; C. gloeosporioides, responsável pela antracnose pós-colheita em frutos e pela antracnose foliar em diversas hortaliças; Corynespora cassiicola, promotor da mancha alvo em soja; Microsporum canis, agente causal de dermatomicoses em animais, e Fusarium solani, promotor da podridão radicular de diversas culturas; essas linhagens de fungos fitopatogênicos foram gentilmente cedidas pela pesquisadora Dr. Dyana Alves Henriques (Universidade São Camilo/SP) e Carlos Roberto Casela (Centro Nacional de Pesquisa Milho e Sorgo). Também foram testadas contra quatro espécies de bactérias patógenas de interesse médico: Enterococcus faecalis (ATCC 29212), Staphylococcus aureus (ATCC 25923), S. saprophyticus (ATCC 43867), Escherichia coli (ATCC 25922); em meio ágar batata dextrose. O teste de antagonismo baseou-se na metodologia de cultura dupla utilizado por Mew \& Rosales (10). A interação foi analisada diariamente até o sétimo dia. Determinou-se a atividade antagônica pela mensuração da inibição do micélio do fungo patogênico em comparação com o controle que continha apenas o patógeno ao centro da placa.

As linhagens que apresentaram resultados positivos, contra todos os fungos testados, foram submetidas novamente ao ensaio em triplicata. As hifas dos patógenos que apresentaram alterações na coloração do micélio próximo a zona de confronto com os isolados endofíticos foram usadas para montagem de lâminas a fim de observar as alterações das mesmas ao microscópio. O experimento foi conduzido em delineamento inteiramente casualizado e as médias submetidas à análise de variância (ANOVA), sendo as médias comparadas pelo teste de Scott-Knott a $5 \%$ de probabilidade.

Atividade antibacteriana dos isolados endofíticos foi avaliada através do teste de antibiose pelo método de sobrecamada (12). Todos os testes foram realizados em triplicata e as medias obtidas posteriormente mensuradas.

Também foi avaliado o potencial das cepas bacterianas em inibir o desenvolvimento de fungos que incidem em grãos de soja, cultivar Pioneer y30, safra 2010/2011; colhido na Fazenda Aricá na cidade de Diamantino-MT.

As bactérias testadas cresceram em caldo nutriente por 24 h, a 28 ${ }^{\circ} \mathrm{C}$ e sob agitação de130 rpm. A suspensão de células de cada linhagem bacteriana foi ajustada no espectrofotômetro UV-VIS (Shimadzu, UV mini 1240) para $A_{540}=0,50$, ajustada com solução salina $0,85 \%$.

Os grãos foram submetidos à assepsia superficial, sendo imersos em solução de hipoclorito de sódio $2,5 \%$ por três minutos, passando, em seguida, por três enxágues sequenciais em água destilada esterilizada; realizando-se a microbiolização de acordo com metodologia modificada de Luz (8). Os grãos desinfestados foram imersos nas suspensões bacterianas por três minutos, sob agitação manual, e distribuídos uniformemente sobre placas de Petri contendo duas folhas de papel de filtro umedecidas. Os grãos do tratamento controle foram imersos em meio de cultura esterilizado. Cada tratamento constituiu-se de 200 grãos, distribuídos em oito repetições de 25 grãos. Após a transferência dos grãos para as placas, elas foram incubadas em câmera de germinação tipo BOD a $25 \pm 1{ }^{\circ} \mathrm{C}$, com fotoperíodo de $12 \mathrm{~h}$, por sete dias. Posteriormente, avaliaram-se os grãos em microscópio estereoscópico, verificando-se a incidência de fungos sobre os grãos de soja.

Para avaliar o potencial antagônico das linhagens endofíticas nos fungos presentes nos grãos de soja, calculou-se a porcentagem de controle de grãos com fungos dos tratamentos pela fórmula:

\section{Pot. Antagônico: $\frac{\mathrm{N}^{0} \text { GCF - N } \mathbf{N}^{0} \text { GMF }}{\mathrm{N}^{\circ} \mathrm{GCF}} \times 100$}

Onde, $\mathrm{N}^{\mathrm{o}}$ GCF representa o número de grãos do tratamento controle com fungos e $\mathrm{N}^{\circ}$ GMF é o número de grãos microbiolizados com fungos. Os dados obtidos foram submetidos à análise estatística pelo teste de Kruskal-Wallis. As bactérias utilizadas nos experimentos, BREI-92 e BREIII-107, foram identificadas pelo sequenciamento do gene 16S, conforme Haas et al. com modificações (3).

Entre as 113 linhagens bacterianas utilizadas no teste de antagonismo, duas - BREI-92 e BREIII-107 - inibiram todos os fungos patogênicos avaliados (Tabela 1). Houve diferenças entre BREI-92 e BREIII-107 na porcentagem de antibiose refletida nas inibições do crescimento micelial.

A antibiose exercida por bactérias sobre patógenos atua por diferentes mecanismos, tais como síntese de substâncias antimicrobianas, competição por espaço e nutriente, secreção de enzimas líticas, alteração de $\mathrm{pH}$ e/ou síntese de compostos voláteis. Os mecanismos de síntese de compostos voláteis e metabolitos secundários têm demonstrado eficiência em inibir o crescimento de fungos (4). Leelassuphakul et al. (4) observaram que a inibição do micélio de fitopatógenos através da produção de metabólitos secundários possui uma maior eficiência quando comparado à síntese de compostos voláteis. A diferença entre a porcentagem de inibição do crescimento do micélio de fungos patogênicos (Tabela 1) pode indicar uma possível distinção entre os mecanismos utilizados por essas linhagens ou ao grau do mecanismo.

Observou-se que as hifas de C. lindemunthianum confrontadas pela linhagem BREIII-107 apresentaram vacuolização e ruptura celular, enquanto as hifas do tratamento controle não apresentaram alterações celulares (Figura 1).

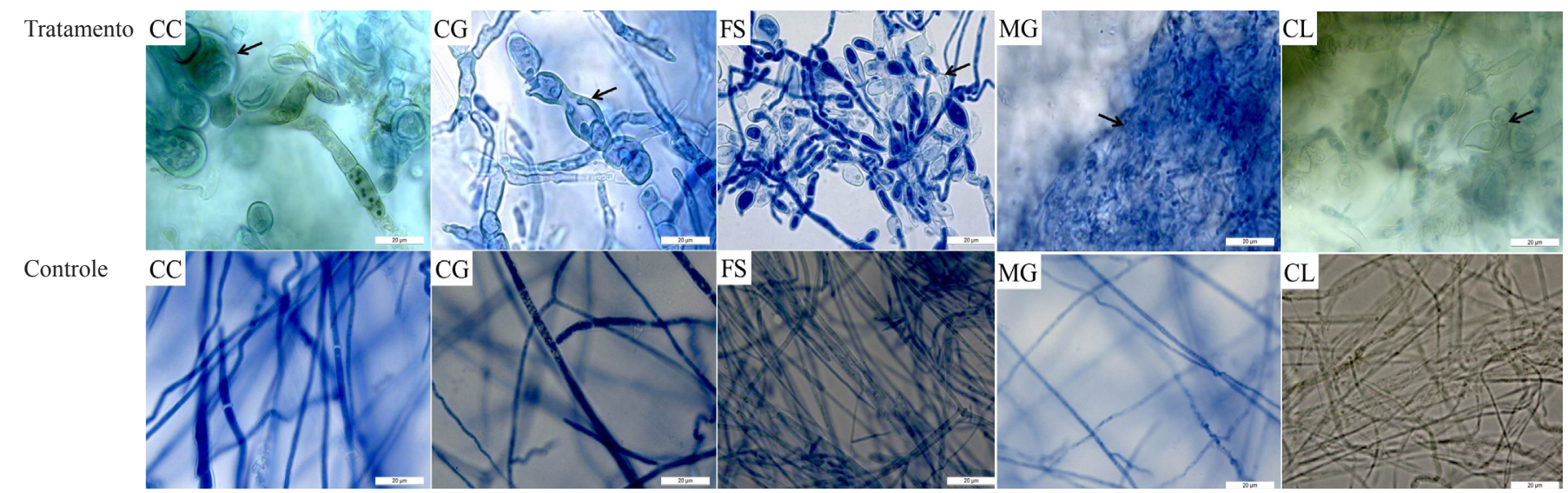

Figura 1. Microfotografia de hifas de fungos patógenos em confronto com a bactéria endofítica Bacillus subtilis BREIII-107 isolada de E. scaber. CC: C. cassiicola, CG: C. gloeosporioides, FS: F. solani, MG: M. canis, CL: C. lindemuthianum. Todas as imagens estão em escala de $20 \mu \mathrm{m}$. 
Tabela 1. Taxa de inibição de fungos patogênicos, controle de crescimento de fungos em grãos de soja e antibiose de bactérias patogênicas por bactérias endofíticas isoladas de E. scaber.

\begin{tabular}{|c|c|c|}
\hline Taxa de inibição de fungos patógenos (\%) & Bacillus subitilis - BREIII-107 & Bacillus sp - BREI-92 \\
\hline Colletotrichum lindemunthianum ${ }^{1}$ & $53,4 \mathrm{Ba}$ & $44,2 \mathrm{Bb}$ \\
\hline Corynespora cassiicula $^{1}$ & $40,7 \mathrm{Ca}$ & $6,4 \mathrm{Db}$ \\
\hline Colletotrichum gloeosporioides ${ }^{1}$ & $53,6 \mathrm{Ba}$ & $19,6 \mathrm{Cb}$ \\
\hline Fusarium solani ${ }^{1}$ & $31,1 \mathrm{Da}$ & $20,1 \mathrm{Cb}$ \\
\hline Microsporum canis ${ }^{1}$ & $59,4 \mathrm{Aa}$ & $52,9 \mathrm{Ab}$ \\
\hline Controle do Crescimento de fungos (\%) & Bacillus subitilis - BREIII-107 & Bacillus sp - BREI-92 \\
\hline Grãos de soja & $97 \mathrm{a}$ & $95 \mathrm{a}$ \\
\hline Halo de inibição em bactérias patógenas (cm) & Bacillus subitilis - BREIII-107 & Bacillus sp - BREI-92 \\
\hline Enterococcus faecalis ${ }^{2}$ & 1,76 & - \\
\hline Staphylococcus aureus ${ }^{2}$ & 1,66 & - \\
\hline Staphylococcus saprophyticus ${ }^{2}$ & 2,23 & - \\
\hline Escherichia coli ${ }^{2}$ & - & - \\
\hline
\end{tabular}

As médias seguidas pela mesma letra, maiúscula entre espécies de fungos e minúscula entre bactérias, não diferem estatisticamente entre si. Foi aplicado o Teste de Scott-Knott a 5\% de probabilidade para analise da taxa de crescimento de fungos patógenos e o teste de kruskal-Wallis para Controle de crescimento de fungos em grãos de soja. ${ }^{1}$ Fungos patogênicos; ${ }^{2}$ Bactérias patogênicas.

Esse efeito de vacuolização já foi descrito anteriormente (4), como sendo causado pela produção de lipopeptídeos que modificam a permeabilidade da membrana do fungo e da composição lipídica, provocando uma diferenciação na hifa do fungo em contato com esse composto. Porém, a produção de enzimas líticas, produzidas por bactérias, como a quitinase, também interfere na lise da parede das células dos fungos patógenos, como descrito para o fungo fitopatógeno Fusarium oxysporum (6).

A bactéria BREI-92 não inibiu nenhuma das espécies de bactérias patógenas testadas, enquanto BREIII-107 inibiu E. faecalis, S. aureus, S. saprophyticus nas condições avaliadas. A inibição variou entre as espécies patogênicas, chegando a 1,66; 1,76 e 2,23 cm de halo, para $S$. aureus, E. faecalis e S. saprophyticus, respectivamente. Esse resultado está de acordo com outros trabalhos realizados com linhagens de bactérias do gênero Bacillus capaz de inibir o crescimento de bactérias patógenas de humanos como S. aureus (1).

A sequência parcial do gene $16 \mathrm{~S}$ do rDNA demonstrou que as linhagens bacterianas obtidas no presente estudo pertencem ao gênero Bacillus quando comparadas a sequencias depositadas no GenBank, sendo que BREI-92 apresentou 98\% de identidade com a espécie Bacillus pumilus (KC771046.1) e Bacillus sp (KF777469.1), BREIII-107 demonstrou 98\% de identidade por Bacillus subtilis (KF640213.1). As linhagens foram denominados Bacillus sp. BREI-92 (KF978126) e Bacillus subtilis BREIII-107 (KF978127).

Vale ressaltar que Bacillus é um gênero de bactéria com grande importância em programas de controle biológico, prospecção de metabólitos bioativos e com alta capacidade de exercer antibiose resultante de compostos antimicrobianos (5). Este gênero, quando em condição endófita, pode auxiliar no desempenho de seu hospedeiro impedindo a colonização de organismos patogênicos (1). Ele é comumente encontrado nos tecidos internos de diferentes hospedeiros como Prunus mume (6), Panax notoginseng (9) e Platycodon grandiflorum (1).

As linhagens bacterianas denominadas Bacillus sp. BREI-92 e o Bacillus subtilis BREIII-107 foram eficientes na inibição do desenvolvimento de fungos filamentosos sobre os grãos de soja. A inibição do aparecimento de fungos sobre os grãos chegou próxima a 100\% quando comparadas à testemunha (Tabela 1). Estudo usando bactérias indica a eficiência do gênero Bacillus no controle do desenvolvimento de patógenos em sementes de milho, $\operatorname{arroz}(7,8)$.

A descoberta do potencial antifúngico de Bacillus $s p$ BREI-92 e Bacillus subtilis BREIII-107 abre uma gama de possibilidades de estudos que visam controlar a incidência de patógenos pós-colheita em grãos de soja, sendo necessários estudos sobre a interação bactéria endofítica-soja a fim de verificar a atuação benéfica dessas linhagens a serem usadas como bioprotetores em grãos de soja.

Das 113 bactérias testadas, as linhagens BREI-92 e BREIII-107 possuem potencial antagônico a cinco espécies de fungos patogênicos: C. lindemunthianum, C. gloeosporioides, C. cassiicula, F. solani, M. canis.

O potencial inibitório destas linhagens resultou na redução de aproximadamente $100 \%$ do crescimento de fungos em grãos de soja, quando avaliadas em condições in vitro, constituindo uma excelente ferramenta de controle biológico.

\section{REFERÊNCIAS BIBLIOGRÁFICAS}

1. Islam, S. M. A.; Math, R. K.; Kim, J. M.; Yun, M. G.; Cho, J. J.; Kim, E. J.; Lee, Y. H.; Yun, H. D. Effect of Plant Age on Endophytic Bacterial Diversity of Balloon Flower (Platycodon grandiflorum ) Root and Their Antimicrobial Activities. Current Microbiology, New York, v. 61, n. 4, p. 346-356, 2010.

2. BACON, C. W.; HINTON D. M. Microbial Endophytes: Future Challenges. Springer India, New Delhi, n. 7. p. 441-451, 2014.

3. Haas, B.J.; Gevers, D.; Earl, A. M.; Feldgarden, M.; Ward, D. V.; Giannoukos, G.; Ciulla, D.; Tabbaa, D.; Highlander, S. K.; Sodergren, E.; Methe, B.; DeSantis, T. Z.; Petrosino, J. F.; Knight, R.; Birren, B. W. Chimeric 16S rRNA sequence formation and detection in Sanger and 454-pyrosequenced PCR amplicons. Genome Research, Cold Spring Harbor, New York, v. 1, n. 21, p. 494-504, 2011.

4. LEELASUPHAKUL, W.; HEMMANEE, P.; CHUENCHITT, S. Growth inhibitory properties of Bacillus subtilis strains and their metabolites against the green mold pathogen (Penicillium digitatum Sacc.) of citrus fruit. Postharvest Biology and Technology, Amsterdam, v.48, n.1, p.113-121, 2008.

5. Li, H.; Wang, X.; Han, M.; Zhao, Z.; Wang, M.; Tang, Q.; Liu, C.; Kemp, B.; Gu, Y.; Shuang, J.; Xue, Y. Endophytic Bacillus subtilis ZZ120 and its potential application in control of replant diseases. African Journal of Biotechnology, Nairobi, Kenya, v.11, n.1, p.231-242, 2012.

6. LI, J. YANG, Q.; ZHAO, L.; ZHANG, S.; WANG, Y.; ZHAO, X. Puri- 
fication and characterization of a novel antifungal protein from Bacillus subtilis strain B29. Journal of Zhejiang University Science/ B, Zhejiang University Press, v.10, n.4, p.264-272, 2009.

7. LUDWIG, J.; MOURA, A. B.; SANTOS, A. S.; RIBEIRO, A. S. Microbiolização de sementes para o controle da mancha- parda e da escaldadura em arroz irrigado. Tropical Plant Pathology, Lavras, v.34, n.5, p.322-328, 2009.

8. LUZ, W. C. Efeito de bioprotetores em patógenos de sementes e na emergência e rendimento de grãos de milho. Fitopatologia Brasileira, Brasília, v.26, n.1, p.16-20, 2001.

9. MA, L.; CAO, Y. H.; CHENG, M. H.; HUANG, Y.; MO, M. H.; WANG, Y.; YANG, J. Z.; YANG, F. X. Phylogenetic diversity of bacterial endophytes of Panax notoginseng with antagonistic characteristics towards pathogens of root-rot disease complex. Antonie van Leeuwenhoek, Amsterdam, v.103, n.2, p.299-312, 2012.

10. MEW, T. W., ROSALES, A. M. Bacterization of rice plants for control of sheath blight caused by Rhizoctonia solani, Phytopathology, Saint Paul, v.76, n.11, p.1260-1264, 1986.

11. POTT, V. J.; POTT, A. Plantas aquáticas do pantanal. 1 ed. Embrapa, Brasília, 2000, p. 80 a 89.

12. PUGSLEY, A. P.; B. Oudega. Methods for studying colicins and their plasmids. Plasmids, a practical approach. Press, Oxford, United Kingdom. p. $105-161,1987$. 